\title{
Anaphor Resolution in Children with Poor Reading Comprehension
}

\author{
Myungsoo Kim ${ }^{\mathrm{a}}$, Mina Hwang ${ }^{\mathrm{b}}$ \\ ${ }^{a}$ Department of Speech and Language Pathology, Graduate School, Dankook University, Yongin, Korea \\ ${ }^{b}$ Department of Special Education, Dankook University, Yongin, Korea
}

Correspondence: Mina Hwang, PhD

Department of Special Education, Dankook

University, 152 Jukjeon-ro, Suji-gu, Yongin 16890,

Korea

Tel: +82-31-8005-3816

Fax: $+82-31-8021-7228$

E-mail: hwangm@dankook.ac.kr

Received: July 5, 2017

Revised: August 17, 2017

Accepted: August 23, 2017

This paper is based on the master's thesis of the first author.
Objectives: This study investigated anaphor resolution during discourse reading in children with poor reading comprehension. Methods: The participants were 13 children with poor reading comprehension and 13 typically developing children in grades 3 to 6 . The children performed an online reading task where they were presented 40 discourses of two sentences where the first sentence containing two antecedents and the second containing an anaphor. The discourses were divided into half based on the types of cues that the children could utilize for anaphor resolution: categorical cues and contextual cues. The children were asked to press a button as soon as they comprehended each sentence and the reading times were measured online. A verification sentence followed each discourse to confirm the children's anaphor resolution. Results: The reading time of the sentences with an anaphor were significantly slower in the poor comprehenders compared to the typically developing children. The typically developing children read anaphor sentences with categorical cues faster than those with contextual cues. However, the poor comprehenders read anaphor sentences with contextual cues faster than those with categorical cues. Conclusion: The poor comprehenders' performances during the online reading task indicated that they had difficulties in anaphor resolution. In addition, the poor comprehenders and the typically developing children appeared to be different in utilizing the two types of cues (categorical and contextual cues) during the process of anaphor resolution.

Keywords: Children with poor reading comprehension, Anaphor resolution, On-line reading task
읽기과정은 글자의 해독을 의미하는 음운해독과(decoding)과 정보 이해를 의미하는 언어이해(linguistic comprehension)로 이루 어진다. 음운해독에서는 문제를 보이지 않고 언어이해에서만 문제 를 보이는 경우를 읽기이해부진(poor comprehender)이라고 한다 (Catts \& Kamhi, 2005). 읽기이해는 단어나 문장을 넘어선 덩이글 (text) 이해를 의미한다. 덩이글 이해는 문장 간의 응집성있는 심적 표상을 형성하는 과정이다(Van Dijk \& Kintsch, 1983). 응집성 형 성의 중심 개념으로 결속성이 있다. 결속성은 기존 정보(given information)와 새로운 정보(new information) 사이를 연결하여 문 장을 통합하게 해주는 것으로 참조관계와 인과관계로 분류된다 (Halliday \& Hassan, 1976). 참조관계란 글을 통해 대상에 대한 표 상을 형성하고 글이 지칭하고 있는 대상과 연결하는 것이다. 덩이
글에서의 참조관계란 한 번 제시되었던 개념을 이후에 반복하여 언 급하는 것이다. 다시 언급한 개념을 이전에 제시되었던 개념의 표상 과 연결하여 기존 정보와 새로운 정보에 대한 통합적인 표상을 형 성할 수 있다. 덩이글의 참조관계를 위해 많이 사용되는 것이 대용 표현이다. 개념을 반복하여 언급하는 것이 대용어(anaphor)이고 이 전에 제시된 개념이 선행어(antecedent)이다(Bang, 1990). 대용어 에 대한 선행어는 단어뿐만 아니라 하나의 개념으로서의 문장 또 는 문단이 될 수 있다. 따라서 대용어와 선행어간의 참조관계 연구 는 읽기이해 과정의 전반을 이해하기 위해 중요할 것이다. 이에 본 연구는 읽기이해부진 아동의 읽기이해 특성을 이해하기 위해 읽기 이해부진 아동과 일반아동의 대용어 참조해결을 살펴보았다.

선행연구에서 살펴본 바에 따르면 읽기이해부진 아동은 어휘, 작 
업기억, 추론과 같이 성공적인 읽기이해를 위해 필요한 많은 영역 에서 일반아동에 비해 낮은 수행을 보인다고 보고하고 있다(Cain 2006; Cain, Oakhill, \& Bryant, 2004; Jeong, 2009). 선행연구들은 읽기이해부진 아동이 가지고 있는 읽기이해에 필요한 영역별 수준 을 파악함으로써 읽기이해부진 아동의 읽기이해에 어려움을 보이 는 원인을 규명하고 이를 통해 읽기이해부진 아동의 판별을 위한 예측변인으로 활용하고 있다. 반면 읽기이해부진 아동의 읽기처리 과정에 대한 연구는 부족한 실정이다. 읽기이해부진 아동의 읽기이 해의 어려움을 이해하기 위해서는 읽기이해에 필요한 어휘, 작업기 억, 추론 둥의 영역에 대한 연구와 함께 읽기처리 과정의 연구가 필 요할 것이다. 국내에서 읽기이해부진 또는 읽기능력이 다른 참가자 들을 대상으로 덩이글 수준에서 읽기처리 과정을 살펴본 연구는 인과적 관계의 덩이글의 응집성에 영향을 미치는 접속부사, 연결어 미 같은 결속장치들에 대해 이루어졌다(Nam et al., 2004; Shon, Hwang, \& Choi, 2015). 본 연구에서는 인과관계와 함께 글의 응집 성 형성에 영향을 미치는 참조관계에서 읽기이해부진 아동의 읽기 처리 과정을 살펴보고자 하였다.

대용어를 사용하면 명사의 반복이나 고유명사를 통해 참조관계 를 형성할 때와 달리 하나의 단어가 아닌 문장 또는 글 전체에 대해 참조관계를 형성할 수 있어 효율적인 글 이해가 가능하다. 참조관 계를 형성하는 과정에서 대용어가 제시되기 이전 글에 대한 표상 을 형성하고 대용어를 읽으면 표상 내에서 대용어가 지시하는 선행 어를 찾기 위한 탐색과정을 진행한다. 이러한 과정을 대용어 참조 해결이라고 하고 이는 통사나 화용 등 다양한 요인들이 상호적으로 작용하는 복잡한 과정이다(Lee, 2009). 대용어인 명사구나 대명사 를 사용할 경우 대용어가 지시하는 선행어를 이전 글을 읽으면서 형성한 표상에서 탐색해야 하므로 대용어를 포함한 문장의 읽기시 간이 늘어난다(McKoon \& Ratcliff, 1980). 따라서 대용어 문장읽기 시간의 측정을 통해 대용어 참조해결의 효율성을 확인할 수 있다.

대용어 참조해결은 언어기반적 단서(language-based cues)와 지 식기반적 단서(language-based cues)를 통해 이루어진다(Bang, 1990; Just \& Carpenter, 1987; Lee, 2006, 2009). 언어기반적 단서에 는 대용어가 가진 특성을 통해 대용어 참조해결을 시도하는 통사 단서(성별, 단.복수형)와 의미단서(범주)가 있고 지식기반적 단서는 대용어 전후의 문맥을 통해 대용어 참조해결을 시도하는 문맥단서 가 있다. 일반 성인을 대상으로 한 국내의 선행연구에 따르면 언어 기반적 단서인 통사단서가 지식기반적 단서인 문맥단서에 비해 대 용어 참조해결에 주도적인 역할을 하고 대용어 참조해결의 속도도 빨랐다(Bang, 1990). 대용어 참조해결에 사용되는 단서들은 단서 에 따라 통사적 분석과 의미적 연결, 세상사지식의 적용이 이뤄져
야 한다. 따라서 읽기이해부진 아동의 대용어 참조해결을 단서 간 의 차이로 살펴보면 읽기이해부진 아동이 대용어 참조해결에서 겪 는 어려움의 원인을 알 수 있을 것이다. 이에 본 연구에서는 읽기이 해부진 아동과 일반아동을 대상으로 대용어 참조해결 과정에 있 어서 언어기반적 단서와 지식기반적 단서의 차이를 살펴보았다. 영 미권과 다르게 대명사 표지가 발달하지 않은 한국어에서 통사단서 를 통해 대용어 참조해결을 살펴보는 것은 대용어 참조해결의 특성 을 정확히 파악하는 것에 어려움이 있다고 판단하였다. 본 연구에 서는 대용어 참조해결을 위한 언어기반적 단서를 통사단서 대신에 한국어에서 대용어로 자주 쓰이는 '그+명사' 형태로 의미단서인 범 주단서를 사용하였다. 읽기이해부진 아동의 경우 단어 간 의미관 계를 파악하는 단어유추에서 어려움을 보이고 범주의 경우 학년 이 올라가도 낮은 수준에 머무는 것으로 보고되었다(Jeong, 2009). 따라서 범주단서를 통한 대용어 참조해결을 살펴봄으로써 읽기이 해부진 아동이 가지고 있는 의미관계를 파악하는 능력의 결함이 전체적인 글 이해에 어떤 영향을 미치는지 살펴볼 수 있을 것이다.

읽기이해부진 아동의 대용어 참조해결에 대한 연구를 살펴보면, 읽기이해부진 아동은 일반아동에 비해 대용어 참조해결에서 낮은 수행을 보였다(Ehrlich \& Remond, 1997; Oakhill \& Yuill, 1986). 읽 기이해부진 아동은 작업기억 부담과 추론의 복잡성을 달리하는 문항에서 선행어 강제 선택질문, 대용어 선택, 문장 판단과제 모두 일반아동보다 낮은 수행을 보였다. 또한 읽기이해부진과 일반아동 모두 작업기억의 부담과 추론의 복잡성이 증가할수록 대용어 선택 및 문장 판단과제에서 낮은 수행을 보여 대용어 참조해결 과정이 작업기억과 추론에 영향을 받는 것으로 나타났다. 하지만 이러한 선행연구에서는 연구의 대상이 초등학교 저학년이었고 읽기이해 부진 아동과 일반아동의 차이를 과제에 대한 정답률로 측정하여 읽기이해 과정의 실시간 처리 과정을 직접적으로 확인 할 수 없었 다. 아동들의 대용어 사용과 노출의 빈도가 늘어나고 대용어 참조 해결 능력이 발달하는 때는 학습과정에서 읽기요구가 늘어나는 초 등학교 고학년 시기이다(Hwang, Kim, \& Lee, 2007; Seo, 2005). 본 연구에서는 초등학교 고학년을 대상으로 대용어 참조해결 과정을 통해 읽기이해 과정의 처리 특성을 확인하고자 온라인 문장읽기 과제를 사용하여 대용어 문장의 읽기시간을 측정하였다.

이와 같이 본 연구는 읽기이해부진 아동의 글 이해의 특성을 알 아보고자 글의 응집성에 중요한 역할을 하는 대용어 참조해결 과 정을 살펴보았다. 이를 위해 선행어 문장과 대용어 문장의 두 문장 으로 이루어진 문항을 제작하였고 대용어 참조해결에 사용되는 범 주단서와 문맥단서의 조건별로 대용어 문장의 읽기시간을 비교하 였다. 


\section{연구방법}

\section{연구대상}

본 연구의 대상은 인천지역의 초등학교에 재학 중인 3-6학년 읽 기이해부진 아동 13 명과 일반아동 13 명으로 총 26 명이었다. 집단 별 학년의 구성은 읽기이해부진 아동의 경우 3 학년 2명, 4 학년 2명, 5 학년 7명, 6학년 2명이며 일반아동은 3학년 2명, 4학년 3명, 5 학년 5 명, 6학년 3명이었다. 대상을 선정한 기준은 다음과 같다. 읽기이 해부진 아동은 (1) 지역아동센터의 학습지도 교사가 읽기이해에 어 려움이 있다고 보고한 아동 중, (2) 기초학력검사(KISE-BATT; Park, Kim, Song, Jung, \& Jung, 2008)의 짧은 글 이해검사 결과가 $25 \%$ ile 이하이고, 음독검사 결과가 $25 \%$ ile 이상이며, (3) 한국어판 웩슬러 아동 지능검사 3판(K-WISC III; Kwak, Park, \& Kim, 2001) 의 동작성 지능검사 결과가 85점 이상인 학생으로 선정하였다. 일 반아동은 (1) 지역아동센터의 학습지도 교사가 읽기이해에 어려움 이 없다고 보고한 아동 중, (2) 기초학력검사(KISE-BATT; Park et al., 2008)의 짧은 글 이해검사 결과와 음독검사 결과가 $25 \%$ ile 이상 이며, (3) 한국어판 웩슬러 아동 지능검사 3판(K-WISC III; Kwak et al., 2001)의 동작성 지능검사 결과가 85점 이상인 학생으로 선정하 였다. 연구대상에 대한 정보는 Table 1에 제시하였다.

\section{연구도구}

본 연구를 위해서 대용어 문장에 대한 온라인 문장읽기과제를 제작하였다. 본 실험의 도구는 태블릿 PC에서 실행가능 하도록 $J \mathrm{JVA}$ 를 이용하여 제작하였다. 본 과제는 2 개의 이어진 문장으로 이루어진 실험문장을 범주단서와 문맥단서의 조건별로 읽고 이해 하는 방식으로 진행하였다. 대용어의 참조해결이 이뤼졌는지 확인 하기 위해 문항 종료 후에 판단문장이 제시되었다. 본 실험은 연습 과제 8 문항, 본 과제 40 문항으로 구성하였다. 본 과제 40 문항은 대

Table 1. Participants' characteristics

\begin{tabular}{lccc}
\hline & $\begin{array}{c}\text { Poor compre- } \\
\text { henders }(\mathrm{N}=13)\end{array}$ & $\begin{array}{c}\text { Normal readers } \\
(\mathrm{N}=13)\end{array}$ & $t$ \\
\hline Age (yr) & $11.58(.96)$ & $11.63(1.07)$ & .115 \\
K-WISC-III (standard scores) & $101.84(7.50)$ & $108.69(14.47)$ & 1.514 \\
KISE-BATT (raw scores) & & & \\
Decoding test & $24.38(1.45)$ & $24.69(.85)$ & .661 \\
Text comprehension test & $7.77(2.86)$ & $20.92(6.25)$ & $6.898^{* * *}$ \\
\hline
\end{tabular}

Values are presented as mean (SD).

K-WISC III = Korean Wechsler Intelligence Scale for Children-III (Kwak, Park, \& Kim, 2001); KISE-BATT = Korea Institute for Special Education-Basic Academic Achievement Test (Park, Kim, Song, Jung, \& Jung, 2008).

${ }^{* * *} p<.001$.
용어의 범주단서, 문맥단서의 2 가지 조건에 대하여 각각 10 문항씩 20 문항과 채움문항 20 문항으로 구성하였다.

본 연구에 사용한 문항은 다음과 같은 절차에 따라 제작되었다. 실험 문항은 선행어 문장과 대용어문장의 두 문장으로 이루어졌 다. 선행어 문장은 첫 번째 선행어와 두 번째 선행어 모두가 주격인 병렬문장의 형식을 택하였다(예: 축구는 신발을 신고 수영은 안경 을 쓴다). 대용어 문장은 “그+명사(범주어)" 형태의 대용어를 목적 격으로 하는 단문으로 구성하였다(예: 지혜는 그 운동을 잔디밭에 서 했다). 선행어의 위치에 따른 영향을 배제하기 위해 대용어에 해 당하는 목표 선행어는 첫 번째 선행어와 두 번째 선행어를 각 5:5의 비율로 구성하였다. 대용어로 사용되는 명사구의 범주유형은 아 동들이 쉽게 이해할 수 있는 채소, 동물, 학용품, 가구, 운동으로 하 였고 각 범주유형 별로 범주단서 2 문항, 문맥단서 2 문항을 제작하 였다. 음절에 따른 읽기시간 오차를 배제하고자 대용어 문장은 14 음절의 단문으로 구성하였다. 실험에 사용된 어휘는 아동들이 이 해하는데 어렵지 않도록 등급별 국어 교육용 어휘(Kim, 2003)의 1-3등급 내에서 선정하였다.

범주단서 문항은 선행어 문장에서 두 선행어를 '독서', '탁구'와 같이 범주를 달리하여 대용어인 '그 운동’만으로 선행어를 선택할 수 있도록 제작하였다. 그리고 대용어 뒤의 문맥은 '화요일마다 했 다'와 같이 두 선행어 모두에 적용 가능한 중립적 문맥을 갖도록 하 여 선행어 선택에 영향을 미치지 않도록 하였다.

문맥단서 문항은 선행어 문장에서 두 선행어를 ‘축구’, ‘수영’처럼 같은 범주를 사용하여 대용어 문장에서의 대용어인 '그 운동'만으 로는 선행어를 선택할 수 없도록 제작하였다. 하지만 대용어 뒤의 문맥은 ‘잔디밭에서 했다.'와같이 ‘축구’에만 적용되는 편중적 문맥 을 갖도록 하여 문맥에 따라 선행어를 선택할 수 있도록 하였다. 문 맥은 아동들이 가진 세상사지식을 통해 충분히 이해할 수 있는 수 준으로 구성하였다.

채움문항은 대용어 없이 두 선행어 중에 하나를 대용어 자리에 넣어 대용어 참조해결이 필요하지 않은 문장으로 구성하였다. 채움 문항은 각 범주유형별로 4 문항씩 제작하여 대용어 참조해결에 대 한 학습효과를 배제하도록 하였다.

본 실험문항은 언어병리학 석사과정에 재학 중인 2 급 언어치료 사 10 명을 대상으로 문항의 내용과 난이도에 대한 타당도를 검증 하였다. 타당도 검증에서 내용과 난이도에 문제가 있다고 판단된 문항은 수정하였다. 초등학교 3-5학년 아동 9명을 대상으로 예비 실험을 실시하여 확인한 결과 이해가 어려운 단어는 없었고, 판단 문장에서 오답이 많은 문항은 수정하여 난이도를 조절하였다. 본 실험에서 사용된 문장의 예는 Appendix 1에 제시하였다. 


\section{연구절차}

본 실험은 안드로이드 태블릿 PC LG Gpad 10.1을 이용하여 지역 아동센터의 교실과 같이 조용한 환경에서 개별적으로 진행하였다.

본 과제의 시행절차는 다음과 같다. 아동들은 검사자가 진행하 는 교육시행과 8 문항의 연습시행을 거치고, 40 문항의 본 검사를 수 행하였다. 테블릿 화면에 준비를 의미하는 “******” 표시가 나타나 고 검사자가 시작하세요'라고 지시를 하면 아동은 ENTER 버튼을 눌러시작하였다.

아동에게 제시되는 문항은 화면 중앙에 문장단위로 제시되고 첫 번째 문장인 선행어 문장을 읽은 아동이 ENTER 버튼을 누르 면 선행어 문장이 사라지고 대용어 문장이 나타났다. 아동이 선행 어 문장을 읽고 ENTER 버튼을 누른 순간부터 대용어 문장을 읽 고 ENTER 버튼을 누를 때까지의 시간이 $1 / 1,000$ 초 단위로 프로그 램에 기록되었다. 아동이 대용어가 포함된 문장을 읽고 ENTER 버 튼을 누르면 대용어 참조해결을 확인하는 판단문장이 제시되었다. 아동은 판단문장에 대한 답을 '예'와 '아니오'의 버튼 중에 하나를 골라 답했다. 판단문장의 정답은 '예’와 ‘아니오'가 5:5의 비율로 제 시되었다. 모든 문항들은 무선적인 순서에 따라 제시되어 각 아동 마다 다른 순서의 과제를 수행하였다. 아동 한 명 당 약 15 분 정도 의 시간이 소요되었다.

\section{자료 분석 및 처리}

본 연구는 범주단서와 문맥단서 조건에 따른 대용어의 참조해결 과정을 알아보고자 본 과제를 분석하고, 대용어가 포함되지 않은 조건에서의 집단 간 읽기시간 차이를 확인하기 위하여 채움문장을 분석하였다. 범주단서와 문맥단서에 따른 집단 간 차이를 확인하기 위하여 대용어가 포함된 문장의 읽기시간의 평균과 표준편차를 구 하였다. 대용어가 포함된 목표문장의 읽기시간이 전체 평균의 \pm 2 표준편차를 넘거나, 대용어 참조해결 확인하기 위한 판단문장에서 오답을 한 문항들은 분석에서 제외하였다. 판단문장의 오답률은 읽기이해부진 아동 $8.08 \%$ 와 일반아동 $6.15 \%$ 로 두 집단 간에는 유 의미한 차이가 없었다 $(t=-.886, p>.05)$. 분석에서 제외한 문항의 비율은 전체문항 중에서 읽기이해부진 아동 $9.61 \%$, 일반아동 $9.03 \%$ 였다. 본과제의 총 520 문항 $(20$ 문항 $\times 26$ 명) 중 문맥단서 22 문항, 범 주단서 28 문항을 제외하고 총 470 문항(문맥단서 238 문항, 범주단 서 232문항)을 분석하였다.

읽기이해부진 아동과 일반아동이 대용어 참조해결 단서에 따른 읽기시간의 차이를 보이는지를 확인하기 위해 집단(2) $\times$ 단서(2)의 이원분산분석(two-way ANOVA)을 실시하였고 범주단서와 문맥 단서 조건은 반복측정(repeated measure)하였다. 자료의 통계처리
Table 2. Descriptive data of reading time (ms) by cue type

\begin{tabular}{lcc}
\hline & $\begin{array}{c}\text { Poor comprehenders } \\
(\mathrm{N}=13)\end{array}$ & $\begin{array}{c}\text { Normal readers } \\
(\mathrm{N}=13)\end{array}$ \\
\hline Categorical cue & $3,512.15(811.77)$ & $2,154.76(388.69)$ \\
Contextual cue & $3,247.23(727.59)$ & $2,344.07(362.72)$ \\
\hline
\end{tabular}

Values are presented as mean (SD).

는 SPSS 18.0 for Window를 사용하였다.

\section{연구결과}

본 과제의 수행 결과 분석 전에 읽기이해부진 아동과 일반아동 의 읽기시간에 차이가 있는지 알아보기 위해 두 집단의 채움문장 의 읽기시간을 분석하였다. 읽기이해부진 아동은 평균 $2,731.69$ $\mathrm{ms}$, 표준편차 $571.94 \mathrm{~ms}$ 였고, 일반아동은 평균 $2,036.00 \mathrm{~ms}$, 표준 편차 $430.26 \mathrm{~ms}$ 로 두 집단 간의 수행은 유의미한 차이가 있었다 $(t=-3.505, p<.01)$. 두 집단의 대용어 참조해결에 따른 읽기시간의 차이만 분석하고자 대용어 문장 읽기시간의 이원분석 시에 채움 문장의 읽기시간을 공변량 처리하였다.

읽기이해부진 아동과 일반아동의 문맥단서와 범주단서 조건별 대용어 문장 읽기시간의 기술통계는 Table 2에 제시하였다. 단서 조 건별 대용어 문장 읽기시간의 이원분산분석 결과 일반아동과 읽기 이해부진아동의 집단의 주효과 $\left(F_{(1,23)}=12.336, p<.01\right)$ 와 집단과 단 서의 상호작용 $\left(F_{(1,23)}=11.696, p<.01\right)$ 이 유의하였고 단서의 주효과 는 유의하지 않았다. 다시 말해서, 읽기이해부진 아동은 일반아동 에 비해 문맥단서와 범주단서 조건 모두에서 대용어 문장 읽기시 간이 유의미하게 느렸다. 또한 집단과 단서의 상호작용이 유의미한 것은 단서에 따른 대용어 문장 읽기시간 속도가 두 집단에서 상반 되는 양상으로 나타났기 때문이다. 일반아동의 경우 범주단서의 대용어 문장을 문맥단서보다 빠르게 읽었지만 읽기이해부진 아동 의 경우 문맥단서의 대용어 문장을 범주단서보다 빠르게 읽는 것 을 확인할수 있었다.

\section{논의 및 결론}

본 연구의 목적은 읽기이해부진 아동과 일반아동의 대용어 참조 해결에서 범주단서와 문맥단서 조건에 따른 차이를 알아보고자 하 였다. 이를 위하여 읽기이해부진 아동들과 일반아동들을 대상으 로 범주단서와 문맥단서의 조건으로 나눠 선행어 문장과 대용어 문장으로 구성된 실험 문항을 읽게 하고 대용어 문장의 읽기시간 을 실시간으로 측정하였다. 그 결과 읽기이해부진 아동들은 일반 
아동들보다 범주단서와 문맥단서 조건 모두에서 대용어 문장의 읽 기시간이 느렸다. 일반아동의 대용어 문장 읽기시간은 범주단서 조 건에서 문맥단서 조건보다 빨랐는데 읽기이해부진 아동의 대용어 문장의 읽기시간은 문맥단서 조건에서 범주단서 조건보다 빨랐다.

일반아동과 읽기이해부진 아동은 판단문장의 오답률에서 유의 미한 차이를 보이지 않아 읽기이해부진 아동이 문항의 내용과 어 휘를 이해하는데 어려움이 없었다. 읽기이해부진 아동과 일반아동 이 채움문장에서 보인 읽기시간의 차이를 공변량 처리한 후 두 집 단 간의 대용어 문장의 읽기시간 차이가 유의미한 것은 읽기이해 부진 아동이 일반아동과의 읽기능력의 차이를 감안해도 대용어의 참조해결 과정에서 일반아동보다 낮은 수행을 보인 것을 의미한다. 따라서 읽기이해부진 아동은 응집성을 형성하는데 중요한 대용어 참조해결 과정에서의 낮은 수행으로 효율적인 읽기에 영향을 받는 것으로 추측된다.

읽기이해부진 아동의 대용어 참조해결에서의 낮은 수행은 읽기 이해부진 아동이 일반아동에 비해 결함을 가진 것으로 알려진 작 업기억과 추론의 영향일 가능성이 있다(Cain 2006; Cain et al., 2004; Jeong, 2009). 본 연구에서는 선행어 문장이 제시된 이후 사라져서 대용어 참조해결을 위해 선행어를 기억해야 하기 때문에 작업기억 에 부담이 있다. 그리고 대용어와 선행어의 범주 판단 과정과 대용 어 이후 문맥을 아동이 가진 세상사 지식과 연결 과정에서 추론이 요구되기 때문이다.

한가지 더 주목할 점은 일반아동이 범주단서 조건에서 문맥단서 조건보다 빠른 읽기시간을 보인 반면 읽기이해부진 아동은 문맥단 서 조건에서의 읽기시간이 더 빨랐다는 것이다. 일반아동의 결과 는 일반 성인을 대상으로 언어기반단서인 통사조건과 지식기반단 서인 문맥조건을 비교한 선행연구의 결과와 유사하다(Bang, 1990). 이는 일반아동에게는 범주단서 조건의 대용어 처리 부담이 문맥조 건에 비해 적지만 읽기이해부진 아동의 경우에는 범주단서를 통해 대용어를 처리하는 것이 부담이 크다는 것이고 대용어 참조해결에 서 범주단서를 효율적으로 활용하지 못한다는 것이다. Jeong (2009) 은 읽기이해부진 아동의 단어유추를 살펴보았는데 그 결과 범주어 의 경우 학년에 따라 능력이 증가하는 순서, 기능, 반의어와 달리 학 년이 올라가도 낮은 수준에 머무는 것으로 보고하였다. 따라서 읽 기이해부진 아동의 낮은 범주어 능력이 범주단서의 효과적인 활용 을 저해하는 하나의 원인일 수 있다.

또한 범주단서 조건이 대용어가 가진 단서로 참조해결을 시도하 는 언어기반단서인 것을 고려할 때, 읽기이해부진 아동이 범주단서 조건에서 낮은 수행을 보인 또 다른 원인은 불필요한 정보를 억제 하는 능력이 낮기 때문일 수 있다. 대용어 참조해결을 위해서는 대
용어에 해당하는 적절한 선행어를 활성화시키고 대용어에 해당하 지 않는 부적절한 선행어나 다른 개념을 억제하여야 한다. Kim과 Lee (1992)는 읽기이해능력에 차이가 있는 성인을 대상으로 대용어 이후 편중된 문맥을 제시한 후에 대용어에 적절한 선행어와 부적 절한 선행어 및 통제단어에 대한 단어 재인 실험을 실시하였다. 읽 기이해능력이 높은 참가자는 적절한 선행어에 대한 반응시간이 부 적절한 선행어와 통제단어에 비해 빨랐고 부적절한 선행어와 통제 단어 사이의 차이는 없었다. 반면 읽기이해능력이 낮은 참가자는 적절한 선행어와 부적절한 선행어 모두 통제단어에 비해 반응시간 이 빨랐고 적절한 선행어와 부적절한 선행어 간의 반응시간 차이 가 없었다. 이와 같이 본 실험에서도 읽기이해부진 아동의 경우 대 용어로 인해 활성화된 두 선행어 중에 부적절한 선행어를 빨리 억 제하지 못하였을 수 있다. 즉, 일반아동의 경우 대용어 참조해결이 대용어를 읽고 즉각적으로 이뤄진다는 주장(Garnham \& Oakhill, 1985)을 고려하면 범주단서 조건에서 대용어를 읽고 이후 문맥과 관계없이 선행어를 결정하였기 때문에 문맥조건에 비해 읽기시간 이 빨랐을 것이라고 추측해 볼 수 있다. 하지만 읽기이해부진 아동 은 범주단서를 통해 선행어를 결정하는데 있어서 활성화된 두 선행 어 중에서 부적절한 선행어를 즉시 억제하지 못하고 선행어 선택과 상관없는 대용어 이후의 문맥까지 처리하면서 작업기억과 추론의 부담이 가중되었을 수 있다.

본 연구는 읽기이해부진 아동의 읽기이해 특성을 대용어에 대한 온라인 과제를 통해 살펴보았다. 읽기이해부진 아동은 읽기이해를 위한 응집성 형성에 중요한 대용어 참조해결에서 낮은 수행을 보이 는 것을 확인할 수 있었다. 또한 대용어 참조해결 시에 일반아동에 비하여 단서를 효과적으로 활용하지 못하였다. 따라서 이후 읽기이 해부진 아동의 중재 시에 아동이 가지고 있는 읽기이해를 위해 필 요한 요인에 대한 중재와 함께 응집성을 형성함으로써 글의 이해에 중요한 역할을 하는 대용어의 활용에 대한 중재가 필요할 것이다.

\section{REFERENCES}

Bang, H. (1990). The contextual effects on reference resolution during text comprehension (Doctoral dissertation). Ewha Womans University, Seoul, Korea.

Cain, K. (2006). Individual differences in children's memory and reading comprehension: an investigation of semantic and inhibitory deficits. Memory, 14, 553-569.

Cain, K., Oakhill, J., \& Bryant, P. (2004). Children's reading comprehension ability: concurrent prediction by working memory, verbal ability, and com- 
ponent skills. Journal of Educational Psychology, 96, 31-41.

Catts, H. W., \& Kamhi, A. G. (2005). Classification of reading disabilities. In H. W. Catts \& A. G. Kamhi (Eds.), Language and reading disabilities (2nd ed., pp.72-93). Boston, MA: Allyn \& Bacon.

Ehrlich, M. F., \& Remond, M. (1997). Skilled and less skilled comprehenders: French children's processing of anaphoric devices in written texts. British Journal of Developmental Psychology, 15, 291-309.

Garnham, A., \& Oakhill, J. (1985). On-line resolution of anaphoric pronouns: effects of inference making and verb semantics. British Journal of Psychology, 76, 385-393.

Halliday, M. K., \& Hassan, R. (1976). Cohesion in English. London: Longman.

Hwang, J. A., Kim, Y. T., \& Lee, J. Y. (2007). Reading comprehension ability in school-aged children. Korean Journal of Communication Disorders, 12, 412-428.

Jeong, M. (2009). The predictors of poor comprehenders reading comprehension in 3 to 6 grades (Doctoral dissertation). Dankook University, Yongin, Korea.

Just, M. A., \& Carpenter, P. A. (1987). The psychology of reading and language comprehension. Boston, MA: Allyn \& Bacon.

Kim, K. (2003). Vocabularies for different levels of Korean educational. Seoul: Parkijung.

Kim, S., \& Lee, M. (1992). Comprehension skill and the efficiency of suppression mechanism in anaphoric reference. Korean Journal of Experimental of Cognitive Psychology, 4, 66-75.

Kwak, G., Park, H., \& Kim, C. (2001). Korean version Wechsler Intelligence Scale for Children (K-WISC-III). Seoul: Special Education.
Lee, J. (2006). Pronoun referential resolution in discourse: the interactive effects of gender marker and mention order in naming task. Korean Journal of Cognitive and Biological Psychology, 18, 39-56.

Lee, J. (2009). Anaphoric reference resolution in expository text: the effects of demonstratives type. Korean Journal of Psychology: General, 28, 547-569.

McKoon, G., \& Ratcliff, R. (1980). The comprehension processes and memory structures involved in anaphoric reference. Journal of Verbal Learning and Verbal Behavior, 19, 668-682.

Nam, K., Kim, H., Park, C., Whang, Y., Kim, Y., \& Sim, H. (2004). The effects of Korean logical ending connective affix on the text comprehension and recall. Korean Journal of Communication Disorders, 9, 51-71.

Oakhill, J., \& Yuill, N. (1986). Pronoun resolution in skilled and less-skilled comprehenders: effects of memory load and inferential complexity. Language and Speech, 29, 25-37.

Park, G., Kim, G., Song, Y, Jung, D., \& Jung, I. (2008). Korea Institute for Special Education-Basic Academic Achievement Test (KISE-BATT). Ansan: Korea Institute for Special Education.

Seo, J. (2005). The realities and instructions of using anaphoric expressions in elementary school students (Master's thesis). Seoul National University of Education, Seoul, Korea.

Shon, J. J., Hwang, M., \& Choi, K. S. (2015). Connective processing in children with poor reading comprehension: focusing on causal and additive connectives. Communication Sciences \& Disorders, 20, 510-517.

Van Dijk, T. A., \& Kintsch, W. (1983). Strategy of discourse. New York, NY: Academic Press. 
Appendix 1. 범주단서 및 문맥단서 문장 예시

\begin{tabular}{lll}
\hline 범주단서 & 선행어문장 & 독서는 마음을 탁구는 몸을 건강하게 한다. \\
& 대용어문장 & 정희는 그 운동을 화요일마다 했다. \\
& 판단문장 & 정희는 탁구를 했다. \\
문맥단서 & 선행어문장 & 축구는 신발을 신고 수영은 안경을 쓴다. \\
& 대용어문장 & 지혜는 그 운동을 잔디밭에서 했다. \\
& 판단문장 & 지혜는 수영을 했다. \\
채움문장 & 선행어문장 & 태권도는 발로 차고 검도는 죽도로 친다. \\
& 대용어문장 & 진호는 검도를 체육관에서 배웠다. \\
& 판단문장 & 진호는 검도를 배웠다.
\end{tabular}




\section{국문초록}

\section{읽기이해부진 아동의 대용어 참조해결 특성}

김명수 ${ }^{1}$ 황민아

'단국대학교 대학원 언어병리학전공, ${ }^{2}$ 단국대학교 특수교육과

배경 및 목적: 본 연구의 목적은 읽기이해부진 아동의 읽기이해 과정에서 대용어 참조해결 특성을 범주단서와 문맥단서에 따라 살펴보 는 것이다. 방법: 초등학교 3-6학년 읽기이해부진 아동 13 명과 일반아동 13 명을 대상으로 대용어 참조해결에 대해 범주단서와 문맥단 서 조건으로 온라인 읽기과제를 진행하였다. 문항은 선행어 문장과 대용어 문장의 두 문장으로 구성되었다. 문항 이후에 대용어 참조해 결을 확인하는 판단문장이 제시되었다. 아동들은 테블릿으로 제시되는 문항을 문장단위로 읽었고, 대용어 문장의 읽기시간을 실시간 으로 측정하였다. 결과: 읽기이해부진 아동은 두 조건 모두에서 일반아동보다 대용어 문장의 읽기시간이 느렸다. 일반아동은 범주조 건의 대용어 문장읽기 시간이 문맥조건 보다 빨랐지만 읽기이해부진 아동은 문맥조건의 대용어 문장읽기 시간이 범주조건 보다 빨랐 다. 논의 및 결론: 읽기이해부진 아동은 대용어 참조해결에 낮은 수행을 보이고 대용어 참조해결 단서를 적절히 활용하지 못한다는 것 을 확인하였다. 읽기이해부진 아동과 일반아동의 범주단서와 문맥단서에 따른 대용어 참조해결 양상이 다름을 확인하였다.

핵심어: 읽기이해부진 아동, 대용어 참조해결, 온라인읽기과제

본 논문은 제1저자의 석사학위논문을 수정·보완한 것임.

\section{참고문헌}

곽금주, 박혜원, 김청택(2001). 한국판 웩슬러 아동 지능 검사 3판(Korean version Wechsler Intelligence Scale for Children: K-WISC III). 서울: 도서 출판 특수교육.

김광해(2003). 등급별 국어 교육용 어휘. 서울: 박이정.

김선주, 이만영(1992). 이해능력에 따른 대용어 처리시 억압기제의 효율성 차이. 한국심리학회지 인지 및 생물, 4, 66-75.

남기춘, 김현정, 박창수, 황유미, 김영태, 심현섭(2004). 연결어미가 글 이해와 기억에 미치는 효과. 언어청각장애연구, 9, 51-71.

박경수, 김계옥, 송영준, 정동영, 정인숙(2008). 기초학력검사(Korea Institute for Education Basic Academic Achievement Test: KISE-BATT). 안산:

국립특수교육원.

방희정(1990). 글 이해시의 참조관계 해결에 미치는 문맥효과. 이화여자대학교 대학원 박사학위논문.

서주형(2005). 초등학생의 대용표현 사용 실태와 그 지도 방향. 서울교육대학교 대학원 석사학위논문.

손정진, 황민아, 최경순(2015). 읽기이해부진아동의 접속부사 처리 특성: 인과적, 부가적 접속부사를 중심으로. 언어청각장애연구, 20, 510-517.

이재호(2006). 담화글의 대명사 참조해결과정: 명명과제에 반영된 성별표지와 언급순서의 상호작용. 한국심리학회지: 인지 및 생물, $18,39-56$.

이재호(2009). 설명문의 대용어 참조해결과정: 지시사 유형의 효과. 한국심리학회지: 일반, 28, 547-569.

정미란(2009). 초등학교 3-6학년 읽기이해 부진학생의 읽기이해력 예측 변인 탐색. 단국대학교 대학원 박사학위논문.

황진애, 김영태, 이주연(2007). 학령기 아동의 읽기이해력 발달: 중심내용파악, 참조 및 추론능력을 중심으로. 언어청각장애연구, 12, 412-428. 